\title{
Investigation of awake craniotomy cases for elderly patients using dexmedetomidine: Case series
}

Soichi Tanaka, Shunsuke Tachibana, Masahito Omote, Tomohiro Chaki, Yasuyuki Tokinaga, Michiaki Yamakage Department of Anaesthesiology, Sapporo Medical University School of Medicine, Sapporo, Japan

\section{Background}

1. A high quality of awakening is required for awake craniotomy (AC) in order for patients to properly perform neurological tasks during the awake phase.

2. In the guidelines for $A C$ in Japan, there is no particular restriction on age of the patient.

3. In elderly patients (over 65 years of age), we sometimes experience poor quality of awakening and uncontrollable delirium due to anaesthetic agents.

4. Goettel et al. reported a high quality of intraoperative brain mapping and efficacy of sedation when dexmedetomidine (Dex) was used for AC 1).

5. In this study, we investigated whether smooth awakening and comfortable anaesthetic management could be achieved by using Dex concurrently in three elderly patients undergoing AC.

\section{Cases}

Case 1: 82-year-old woman. BMI: 21.14

Case 2: 82-year-old woman. BMI: 21.43

Case 3: 77-year-old woman. BMI: 16.15

※rain tumor resection was planned for all patients.

\section{Anaesthetic management of AC}

Premedication Dexamethasone 3.3mg+Famotidine $20 \mathrm{mg}$

Anaesthesia was induced with propofol, Induction remifentanil and rocuronium.

LMA Supreme ${ }^{\circledR}$ was used for airway management.

Scalp nerve block was performed with

Analgesia $\quad \frac{0.375 \% \text { levobupivacaine. [Figure. } 1]}{\text { ※Local anaesthesia with levobupivacaine was }}$ performed by a surgeon before head pinning.

After induction, we gradually decreased the continuous doses of propofol and remifentanil and started Dex infusion.

BIS targeting BIS index of around 60.

The surgeon cued to awake the patient
we stopped infusing anaesthetic agents.

After confirmation of spontaneous breathing and communication, we removed the LMA.

※Times to extubation were $1 \mathrm{~min}$ (case 1 ), $4 \mathrm{~min}$ (case 2), and $5 \mathrm{~min}$ (case 3). [Table 1]

Anaesthesia was induced with propofol, remifentanil and rocuronium.

Re-induction remifentanil and rocuronium.
LMA Supreme ${ }^{\circledR}$ was used for airway management.

Figure.1 Scalp nerve block in our institution

greater auricular $\mathbf{n}$.

Results

Table1 patients clinical data

\begin{tabular}{|c|c|c|c|c|c|c|c}
\hline $\begin{array}{c}\text { HR(bpm), } \\
\text { BP(mmHg) }\end{array}$ & $\begin{array}{c}\text { Time to } \\
\text { extubation }(\mathrm{min})\end{array}$ & $\begin{array}{c}\text { Prop } \\
(\mu \mathrm{g} / \mathrm{ml})\end{array}$ & $\begin{array}{c}\text { Remi } \\
(\mathrm{ng} / \mathrm{ml})\end{array}$ & $\begin{array}{c}\text { Dex } \\
(\mathrm{ng} / \mathrm{ml})\end{array}$ & $\begin{array}{c}\mathrm{HR}(\mathrm{bpm}), \\
\mathrm{BP}(\mathrm{mmHg})\end{array}$ & $\begin{array}{c}\text { awaking } \\
\text { time }(\mathrm{min})\end{array}$ & $\begin{array}{c}\text { Modified Aldrete Score } \\
\text { after extubation }\end{array}$ \\
\hline $80,126 / 58$ & 1 & 0.1 & 0.023 & 0.44 & $\begin{array}{c}80-82, \\
100-102 / 60-64\end{array}$ & 26 & 12 \\
\hline $78,156 / 98$ & 4 & 0.3 & 0.386 & 0.08 & $\begin{array}{c}78-98, \\
104-116 / 62-64\end{array}$ & 61 & 11 \\
\hline $60,118 / 64$ & 5 & 0.4 & 0.027 & 0.14 & $\begin{array}{c}56-60, \\
120-140 / 60-72\end{array}$ & 33 & 10
\end{tabular}

※Effect-site concentrations of propofol/ remifentanil and plasma concentration of dexmedetomidine after surgery were estimated by the models below. Propofol (Prop), Marsh model, Remifentanil (Remi), Minto model, Dexmedetomidine (Dex), Dyck model.

The quality of awakening was high in all cases, and the patients could perform neurological tasks faultlessly during the awake phase.

\section{Discussion}

- Dexmedetomidine is a selective a2-receptor agonist and has sympatholytic, analgesic, and sedative properties ${ }^{2}$. [Figure2]

- Stevanovic et al. reported that patients in whom dexmedetomidine was used for AC had a shorter arousal time after the first sleep phase3). For elderly patients, intraoperative awake electrical mapping was also associated with better preservation of the patient's neurological status and quality of life compared to surgery under general anesthesia4).

Figure.2 Pharmacological action of dexmedetomidine via a2 receptor

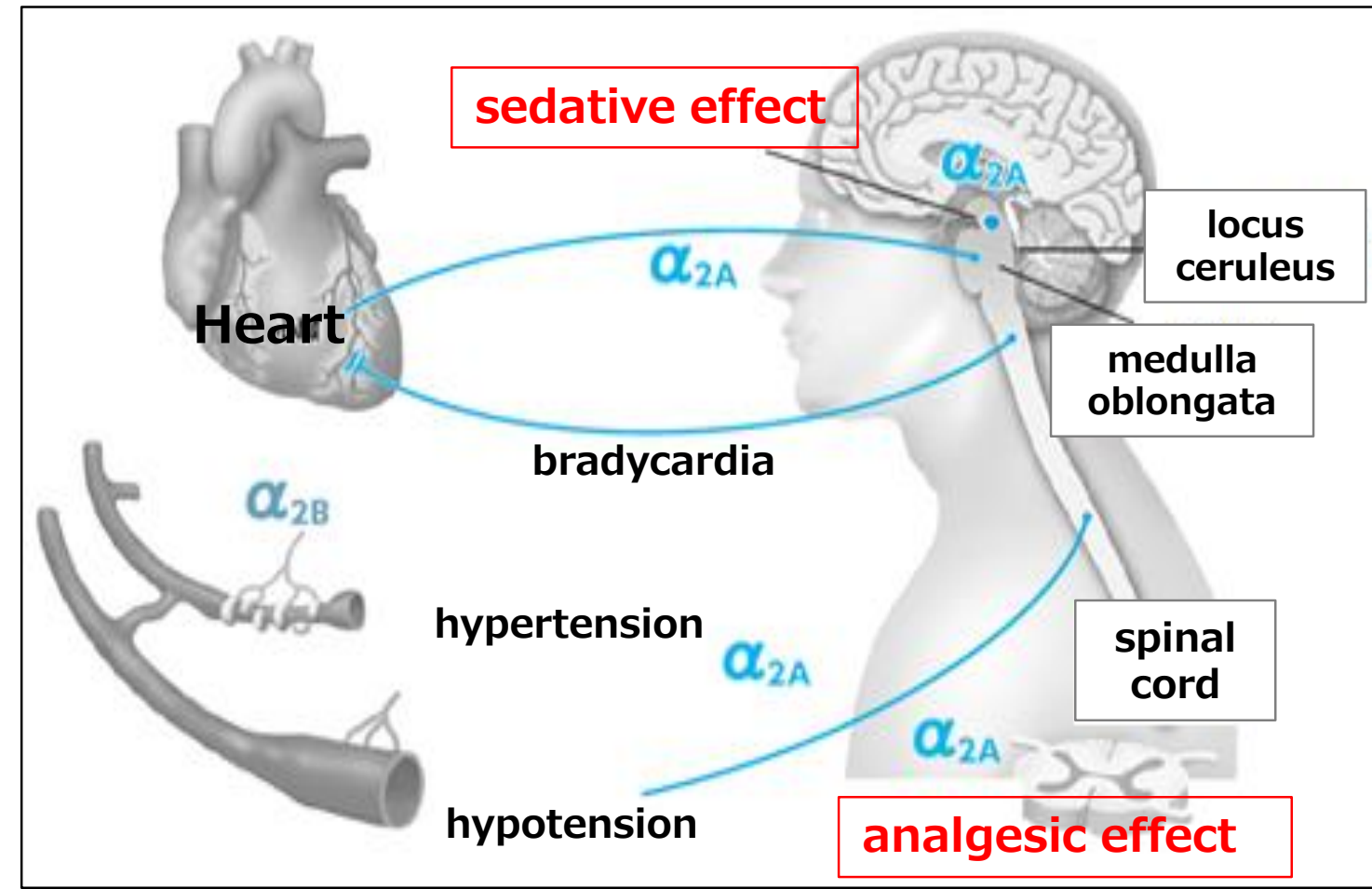

In the elderly patients in whom Dex was used, the time to extubation was short and the quality of awakening was good.

- Dex infusion enabled the intraoperative propofol and remifentanil doses to be reduced and might have provided proper sedation.

- Intraoperative infusion of low-dose Dex stabilized haemodynamics.

\section{Learning point}

\section{Anaesthetic management using} dexmedetomidine concurrently is useful for awake craniotomy in elderly patients.

\section{References}

1. N. Goettel et al. British Journal of Anaesthesia, 116: 811-21 (2016)

2. S.Y.Kim et al, British journal of Anesthesia 2013.111(2):222-8.

3. Stevanovic A et al, PLOS ONE 2016. DOl:10.1371/journal.pone.0156448

4. Grossman R et al, Ann Surg Oncol 2013. 20:1722-8. 